Bioscientia Medicina: Journal of Biomedicine \& Translational Research

Journal Homepage: www.bioscmed.com

\title{
The Influence of Knowledge, Attitudes and Behavior of Cleaning Officers with the Number of Mosquito Larvae in the Water Reservoir Palembang City
}

\author{
Aldi Alfian ${ }^{1}$, Chairil Anwar ${ }^{*}$, Iche Andriyani Liberty ${ }^{3}$ \\ ${ }^{1}$ Medical Education Study Program, Faculty of Medicine, Universitas Sriwijaya, Palembang, Indonesia \\ ${ }^{2}$ Department of Parasitology, Faculty of Medicine, Universitas Sriwijaya \\ ${ }^{3}$ Department of Public Health, Faculty of Medicine, Universitas Sriwijaya, Palembang, Indonesia
}

\section{A R T I C L E I N F O}

\section{Keywords:}

Mosquito larvae

Knowledge

Attitude

Behavior

Public Health

\section{Corresponding author: \\ Chairil Anwar \\ E-mail address: \\ chairil53@fk.unsri.ac.id}

All authors have reviewed and approved the final version of the manuscript.

https://doi.org/10.32539/bsm.v5i3.217

\begin{abstract}
A B S T R A C T
Background Mosquito was one of the animals that can transmit deadly diseases. Information about water reservoirs as their habitat as well as human knowledge, attitudes and behavior factors are considered important to help eradicate mosquito. This study aims to determine the effect of knowledge, attitudes and behavior of cleaners on the number of mosquito larvae in water reservoirs in Palembang. Methods This research was mixed method research (quantitative and qualitative) in the field and laboratory. The research samples were all mosquito larvae and containers found. The research respondents were all cleaning services. Data were collected by interviewing and filling in questionnaires, observing water reservoirs and identifying the types of mosquito larvae in microscope. Results A total of 40 containers were found in Punti Kayu Nature Park. There were 8 containers that were indoors $(20 \%)$ and 32 containers were outdoors $(80 \%)$ with 17 containers contained larvae. Of all the containers that were positive for larvae, 6 were filled with clear water and 11 were filled with turbid water. The number of larvae found were 358 larvae outdoors and 82 larvae indoor with a total of 440 mosquito larvae with the genus Culex spp. and Aedes albopictus species. The index of mosquito larvae were obtained FLI (Free Larva index) $=66,67 \%$, HI (House Index) $=33,33 \%$, CI (Container Index $)=16,67 \%$, BI (Breteau Index $)=33.33 \%$ from the 3 buildings examined. From these results, it was obtained DF (density figure) or density level of 5 . There were 40 containers that could be habitats for Culex spp. and Aedes albopictus. Conclusion The knowledge, attitude and behavior of the cleaning services were good. The number of mosquito larvae could be influenced by the frequency of cleaning and the lack of knowledge of the cleaning services.
\end{abstract}

\section{Introduction}

Mosquitoes are one of the animals that act as vectors of diseases caused by various types of parasites. Diseases caused by mosquitoes include malaria transmitted to humans via the Anopheles mosquito, filariasis by Culex mosquitoes, dengue fever, chikungunya and yellow fever which are transmitted to humans via the Aedes mosquito. ${ }^{1}$

Dengue Hemorrhagic Fever (DHF) is a tropical infectious disease caused by the dengue virus and transmitted by the Ae species mosquito. aegypti and Ae. albopictus as the primary vector. In Indonesia, there were 68.407 dengue cases reported in 2017, with 493 cases of DHF deaths ${ }^{2}$.

The development of DHF cases in Palembang City tends to fluctuate from 2013 to 2017 with the highest incidence in 2015 of 979 with $\mathrm{CFR}=0.20 \%{ }^{3}$. The incidence of DHF is related to environmental factors, namely the availability of breeding places for Aedes mosquito vectors, such as in stagnant and open water, for example barrels, drums, pots, buckets, flower vases, plant stems or leaves, tanks, waste bottles, cans, used tires and others. ${ }^{4}$. 
The spread of DHF in an area must be controlled so that the disease is handled properly. One of them is by controlling and eradicating the dengue vector. This effort can be done by eradicating mosquito nests (PSN) and periodic larva inspection 5 . Community activities in conducting PSN are influenced by various factors, such as knowledge and attitudes ${ }^{6}$.

The absence of information regarding the types of mosquito larvae and their breeding sites in the Punti Kayu Nature Park (TWA) makes it important for this research to be carried out. Information about the types, number of mosquito larvae, and water reservoirs as breeding grounds is very important to know the data on the distribution of mosquito larvae and the influence of knowledge, attitudes and behavior of cleaners on the number of mosquito larvae so that prevention can be done by the local community.

\section{Methods}

This research is a mixed method research (quantitative and qualitative) in the field and laboratory with the type of observational analytic research. The study was conducted from August 2020 to December 2020 at the Punti Kayu Nature Tourism Park, Palembang, the Biooptic Laboratory, and data analysis at the IKM Section of the Faculty of Medicine, Sriwijaya University.

The population consists of all water reservoirs (TPA) and all cleaning officers on duty at the Punti Kayu Nature Park, Palembang. While the samples studied were all TPA and mosquito larvae found in the TPA, as well as all cleaning officers on duty in the Nature Park of Punti Kayu Palembang.

A total of ten cleaners were selected as respondents by means of total sampling. The dependent variable in this study was the number and type of mosquito larvae. The independent variables examined in this study were the knowledge, attitudes and behavior of cleaners. Data collected in the form of characteristics and number of TPA, number of larvae, genus and species of mosquito larvae found. Larvae are caught using gamadotics, dropper drops, and chipping.

\section{Results}

\section{Habitat of Potential Development of Mosquitoes}

A total of 40 water reservoirs (TPA) were found in the area of Punti Kayu Nature Park. There are 8 TPAs that are indoors (20\%) and 32 TPAs are outdoors (80\%). A total of 2 TPA positive larvae indoors and 15 TPA positive larvae outdoors.

There are 32 landfills in the form of fountains, trash bins, buckets, duck boats, natural puddles, lakes, fish ponds, miniatures, gutters, and turtle cages that are outside the room, while there are 8 TPAs in the form of water reservoirs and drums. in the room. Of all the TPAs that were positive for larvae, there were 6 TPAs containing clear water and 11 TPAs containing turbid water.

\section{Number of Mosquito Larvae}

From the results of observations, it was found that positive TPA contained mosquito larvae in the room, namely a drum of 82 mosquito larvae.

For landfills that are outdoors, a total of 358 mosquito larvae were found scattered in the TPA of fountains, trash cans, buckets, duck boats and miniatures.

\section{Mosquito Larva Index}

Based on the data that has been obtained from the research that has been done, it can be calculated that the larva free number (ABJ), the House index (HI), the Container index $(\mathrm{CI})$ and the Breteau index $(\mathrm{BI})$ can be calculated.

\section{Mosquito Larva Genus}

From the identification results using a microscope, it can be seen that the short and fat siphon shape in Figure 1 indicates the characteristics of Aedes larvae.

There is a comb with teeth without lateral spines, it can be seen in Figure 2. The identification results show that the larvae found in the Nature Park of Punti Kayu Palembang belong to the genus Aedes albopictus. This comb is the basis for distinguishing species in the larvae of the genus Aedes mosquito 
Apart from the short and fat siphon, there were also long and slender siphons which are characteristic of the genus Culex. In addition, the anal segment can be seen that the larvae have a closed saddle which is also a characteristic of the genus Culex in Figure 3.

Of the 17 TPAs positive for mosquito larvae, there were 15 TPA (88.24\%) with genus Culex mosquito larvae and 2 TPA (11.76\%) with mosquito larvae from the Aedes albopictus species.

\section{General Characteristics of Respondents}

The general characteristics of respondents can be seen in the following table.

\section{Knowledge, Attitudes and Behavior of Janitors}

The level of knowledge of the cleaners at Punti Kayu Palembang Tourism Park was obtained from interviews and filling out a questionnaire which resulted in 5 cleaners with a good level of knowledge (50\%) and 5 cleaners with a moderate level of knowledge $(50 \%)$. There are 10 cleaners with good attitude (100\%). Good community behavior as many as 10 people (100\%).

\section{Data Triangulation}

In order to maintain the validity of the data, data testing was carried out on the research by means of data triangulation.

Table 1. Types of TPA and Number of Positive and Negative TPA for Larvae

\begin{tabular}{clccccc}
\hline & & & \multicolumn{4}{c}{ Water and larva conditions } \\
\cline { 4 - 7 } No & \multirow{2}{*}{ Type of TPA } & $\mathbf{n}$ & \multicolumn{3}{c}{ Clear } & \multicolumn{3}{c}{ Cloudy } \\
\cline { 4 - 7 } & & 3 & 0 & 1 & 2 & 0 \\
\hline 1 & Water fountain & 4 & 4 & 0 & 0 & 0 \\
2 & Trash can & 4 & 0 & 0 & 4 & 0 \\
3 & Bucket & 4 & 0 & 0 & 4 & 0 \\
4 & Duck boat & 4 & 0 & 4 & 0 & 0 \\
5 & Water storage tub & 4 & 2 & 2 & 0 & 0 \\
6 & Drum & 4 & 0 & 0 & 0 & 4 \\
7 & Natural puddles & 2 & 0 & 0 & 0 & 2 \\
8 & Lake & 2 & 0 & 0 & 0 & 2 \\
9 & Fish pond & 4 & 0 & 0 & 1 & 3 \\
10 & Miniature & 4 & 0 & 4 & 0 & 0 \\
11 & Sewers & 1 & 0 & 0 & 0 & 1 \\
12 & Turtle enclosure & Larvae (-) & Larvae & Larvae \\
\hline
\end{tabular}

Table 2. Larvae in the room

\begin{tabular}{cccc}
\hline No & TPA Type & $\mathbf{N}$ & \% \\
\hline 1 & Drum & 82 & 100.00 \\
\hline & Total & 82 & 100.00 \\
\hline
\end{tabular}

Table 3. Outdoor larvae

\begin{tabular}{clcc}
\hline No & Type of TPA & $\mathbf{n}$ & \% \\
\hline 1 & Water fountain & 96 & 26.81 \\
2 & Trash can & 139 & 38.83 \\
3 & Bucket & 60 & 16.76 \\
4 & Duck boat & 41 & 11.45 \\
5 & Miniature & 22 & 6.15 \\
\hline
\end{tabular}




\begin{tabular}{lll}
\hline Total & 358 & 100.00 \\
\hline
\end{tabular}

Table 4. Mosquito larva index

\begin{tabular}{lc}
\hline Indicator & Parameter value \\
\hline Larva free rate (\%) & 66.67 \\
House index (\%) & 33.33 \\
Container index (\%) & 16.67 \\
Breteau index (\%) & 33.33 \\
Density figure (DF) & 5 \\
\hline
\end{tabular}

Table 5. Genus and species of larvae in each TP

\begin{tabular}{cll}
\hline No & Type TPA & Genus and Spesies Larva \\
\hline 1 & Water fountain & Culex spp. \\
2 & Trash Can & Culex spp. \\
3 & Bucket Aedes & Aedes (Ae. Albopictus) \\
4 & Duck Boat & Culex spp. \\
5 & Drum Aedes & Aedes (Ae. Albopictus) \\
6 & Miniature & Culex spp. \\
\hline
\end{tabular}

Table 6. Distribution of General Characteristics of Respondents

\begin{tabular}{llll}
\hline General characteristics & Category & $\mathbf{n}$ & $\%$ \\
\hline Old (years) & $17-25$ & 8 & 80 \\
& $26-35$ & 2 & 20 \\
\hline Gender & Male & 7 & 70 \\
& Female & 3 & 30 \\
\hline Education level & Did not graduate & 0 & 0 \\
& elementary school & 0 & 0 \\
& Junior High & 1 & 10 \\
& High school & 9 & 90 \\
& College & 0 & 0 \\
\hline Total & & $\mathbf{1 0}$ & $\mathbf{1 0 0}$ \\
\hline
\end{tabular}


Table 7. Data Triangulation of Health Promotion Officers at Punti Kayu Health Center

\begin{tabular}{|c|c|c|c|c|c|}
\hline No & & Item & & Statement & Source \\
\hline 1 & $\begin{array}{l}\text { Mosquito } \\
\text { program }\end{array}$ & vector & control & $\begin{array}{l}\text { "For vector control, there are two, dengue and malaria, } \\
\text { but the only thing that is often reported every month is } \\
\text { DHF. There is also malaria every month but because the } \\
\text { cases are always zero, right? If malaria here, if DHF } \\
\text { depends on the cases in our area. So, for example, there } \\
\text { is a notification from the health office in the Punti Kayu } \\
\text { area, for example, there are two urban villages, Srijaya } \\
\text { and Karya Baru. If someone is affected by dengue fever, } \\
\text { then we will do PE, go to the field to join forces with } \\
\text { surveillance and health promotion officers. But for } \\
\text { malaria, our cases are still } 0 \text { but there are still reports. " }\end{array}$ & ATDP \\
\hline & & & & $\begin{array}{l}\text { "Counseling is sometimes included. For example again } \\
\text { going to the field promkes officers participate in } \\
\text { counseling, if there are cases there. Then we have ABJ } \\
\text { reports every month, right? So that's also promkes to the } \\
\text { residents to do counseling }\end{array}$ & ATDP \\
\hline
\end{tabular}

"Spraying fogging is also the same, if there are cases in ATDP the same area, there are two or three new cases, we will submit them to the health office. Later the health office will carry out fogging depending on the area. If in that area there is only one KK who is affected, it is possible that it was not sprayed with fogging. Because we don't know. That's why we did PE earlier, where did he travel from, where did his family come from, because the mosquitoes could come from outside right? If, for example, there are two or three RTs in the area, there is a high chance that the mosquitoes will be there, then we will do fogging, if there are not periodically. At best, if there is a case there then we PE, we do an analysis, if we need to do some logging, then we propose to the health office, then we will do it. "

"For ABJ, periodic larva checks are carried out every month, and cadres are carried out. Now, one house for one Jumantik cadre is being incessant. So every house must be able to see the cleanliness in the house, especially mosquito larvae. "

"ABJ's separate reports from cadres, for example RT how ATDP many months, from the numbered house until there are or not mosquito larvae, then it is reported to us. For 
example, if there are cases, then we will go to the field.

Surveillance is carried out by officers in particular, we collaborate and health promotion officers provide information to residents. "

"Every time we have a problem, promkes will immediately

ATDP go down, even if the health promotion officers do not go down, the surveillance officers and the environmental health program holders of the DHF program always advise the residents."

"The implementation of health promotion can be from ATDP interviews, counseling, and many more such as brochures, leaflets, and others. The success parameter can be seen from the low DHF case rate seen from the monthly ABJ examination by cadres who are evaluated by DHF officers.

"After they give the report, we will go down too. However, ATDP not all houses, judging from the high cases from the cadres' reports, we only form a recapitulation. For the TWA Punti Kayu itself, health promotion was carried out by providing counseling to visitors and officers there. However, it is done not regularly, most recently in 2019 yesterday. There, we immediately went to check a lot, right? From water samples to environmental health checks. For 2020 this has not been implemented because due to corona, the tourism forest has closed and only opened now

The

ATDP investigation at the Punti A little bit can be seen from the examination of ABJ, if the Kayu Health Center $\mathrm{ABJ}$ score is low it means there are many cases 


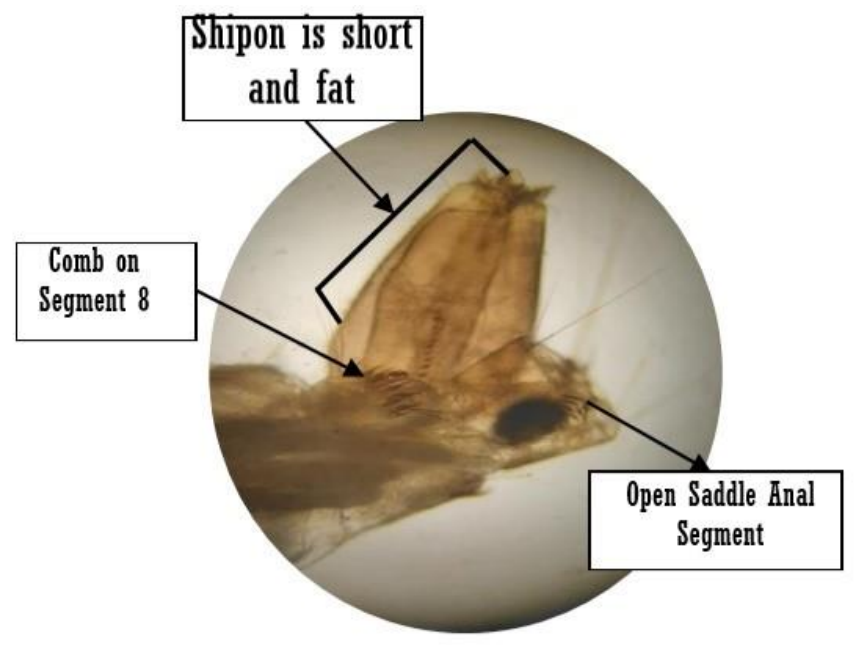

Figure 1. Aedes albopictus larvae (magnification 10x10)

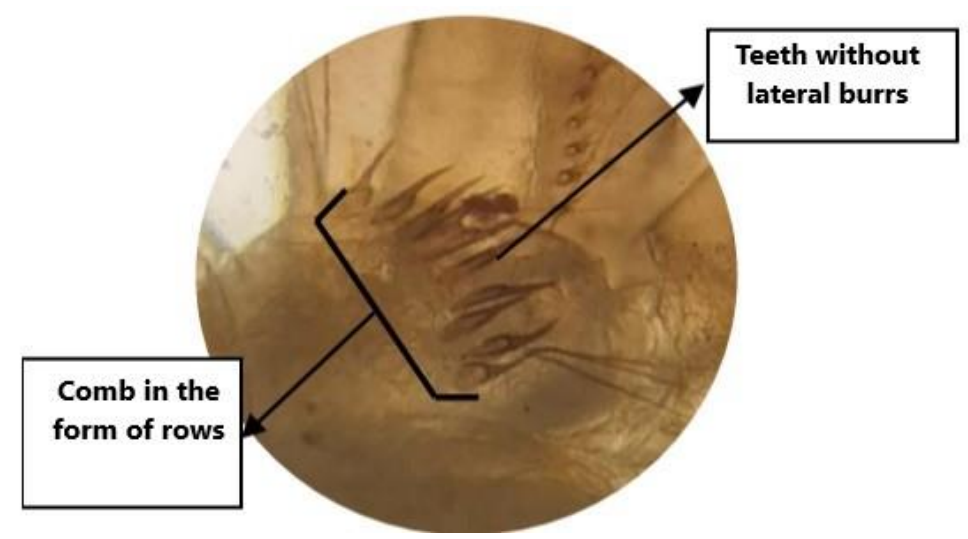

Figure 2.Comb on Aedes albopictus Larvae (Magnification 10x40)

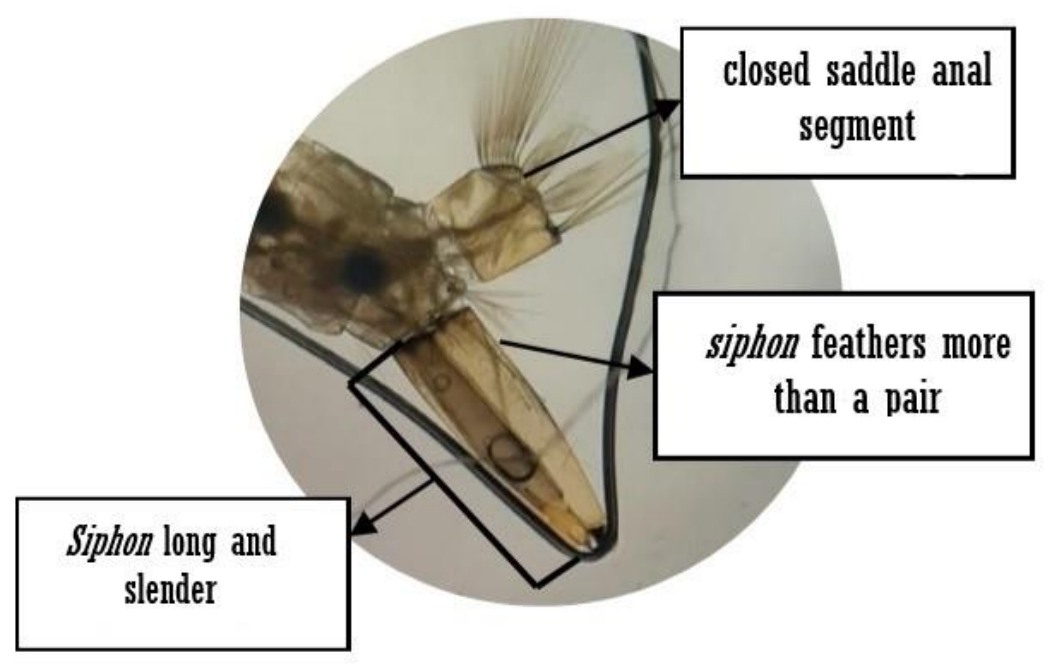

Figure 3. Culex larvae (Magnification 10x4)

\section{Discussion}

\section{Water reservoir as a habitat for mosquitoes}

From the results of research that has been carried out, the type of water reservoir that contains the most mosquito larvae is the trash containing water. Likewise with research which found that there are many 
breeding places which are used goods or garbage around the house such as used paint containers and used tires ${ }^{7}$.

Apart from trash bins, other landfills that have the highest number of mosquito larvae are fountains and containers to hold water. From the research results by (Kinansi et.al), indoor TPA is more of a breeding ground for mosquitoes because mosquitoes prefer places that are far from sunlight and tend to be dark and humid ${ }^{8}$

In the research area there is also a TPA which can be a breeding place for the Mansonia genus mosquitoes, such as lakes and other natural puddles with water plants in it. This is consistent with research conducted by Mading et.al (2014) which states that the presence of fish as a predator of mosquito larvae in water reservoirs affects the number of mosquito larvae. If there is a certain number of fish in a TPA, the number of mosquito larvae will decrease ${ }^{9}$.

\section{Mosquito Larva Species}

Based on the results of observations that have been made, 440 mosquito larvae were found from various landfills. A total of 82 larvae have a siphon which is short and fat with a pair of siphon feathers. There are comb teeth located in a row without lateral spines. There are 358 larvae that have a siphon

long and slender with more than one pair of siphon hairs. This shows that of the 440 samples obtained, 82 of them were Aedes albopictus mosquito larvae and 358 other samples were mosquito larvae from the genus Culex. The absence of Aedes aegypti species is probably due to the limited number of landfills in the room. Because Aedes aegypti larvae prefer indoor TPA which is used for daily use and has clear water.

\section{Number and Density of Mosquito Larvae}

In the results of the research, the most number of mosquito larvae found was the genus Culex which was outside the room. The large number of mosquito larvae is also associated with the number of open landfills that are found in the Punti Kayu Nature Park. According to research conducted by Hadisaputro et al. (2009), that there is a significant relationship between the habit of closing and cleaning the container properly and the presence of Aedes sp. Larvae. in the container ${ }^{12}$.

The results of the House Index (HI) are 33.33\% with a larva free rate (ABJ) of $66.67 \%$, the Container Index (CI) of $16.67 \%$ falls into category 5 , which means that the area has moderate larval density and the Breteau Index (BI) 33.33\% container / building. From these results it can be concluded that the Punti Kayu Tourism Park area has a moderate density of mosquito larvae.

\section{Level of Knowledge, Attitude and Behavior of Janitors}

From the results of the research that has been done, it is found that the good level of knowledge of cleaners is 5 people $(50 \%)$ and 5 people (50\%) are moderate. There are 10 cleaners with good attitude (100\%). Good community behavior is 10 people $(100 \%)$. In general, the level of knowledge, attitude and behavior of cleaners at Punti Kayu Palembang Nature Park is good.

From the results obtained, the level of attitude and behavior of cleaners that are already good is the result of the efforts of health promotion officers who always conduct outreach to the community, such as counseling about PHBS (Clean and Healthy Living Behavior). In addition, the development of jumantik cadres was carried out with the movement of one house and one jumantik in the working area of the Punti Kayu Health Center.

Therefore, the knowledge, attitudes and behavior of cleaners in the TWA Punti Kayu area are quite good. Some cases are still found, possibly due to other factors, such as the frequency of cleaning and also because the COVID-19 pandemic has made some activities difficult. This good knowledge, attitude and behavior is not only caused by the individual cleaning staff respondents being interviewed, but also supported by the activities of the puskesmas officers who always come down to carry out regular checks and counseling.

\section{Conclusion}

1. There were 40 TPAs (8 indoor, 32 outdoor) that 
were observed to have the potential to be breeding grounds for mosquitoes, namely in the form of fountains, trash cans, buckets, drums, duck boats, and miniatures.

2. The number of mosquito larvae obtained was 142 Ae. albopictus and 298 larvae of Culex sp.

3. The genus and species of mosquito larvae found were Ae. albopictus and Culex sp.

4. The index of mosquito larvae was obtained by Larva Free Rate $(\mathrm{ABJ})=66.67 \%$, House Index $(\mathrm{HI})=33.33 \%$, Container Index $(\mathrm{CI})=16.67 \%$, and Breteau Index $(\mathrm{BI})=33.33 \%$. This shows the density of mosquito larvae or Density Figure (DF) at 5 (moderate).

5. The level of knowledge of cleaners is good (50\%) and some are moderate (50\%). The attitude level of the cleaners is all good (100\%). The behavior level of cleaners is all good (100\%).

6. From the data obtained, the knowledge, attitudes and behavior of the janitor are good. However, some mosquito larvae were still found in the study area. This can be influenced by the frequency of cleaning and the lack of knowledge of the cleaning staff.

\section{References}

1. World Health Organization (WHO). 2017. Mosquito-borne diseases.

2. Anwar, C., Lavita, R., \& Handayani, D. 2014. Identification and Distribution of Aedes sp. as a vector of dengue hemorrhagic fever in several regions in South Sumatra. Sriwijaya Medical Magazine, 46 (2), 111-117.

3. Palembang City Health Office. 2017. Health Profile in 2017. Health Profile of Palembang City in 2017.

4. Suryani, S., \& Sari, D. O. 2018. Relationship between 3M Behavior and Dengue Hemorrhagic Fever in the Work Area of the West Ring Health Center, Bengkulu City. HIGIENE: Journal of Environmental Health, 3 (3), 132-136.
5. Nugroho, A. D. 2011. Mortality of Aedes aegypti larvae after giving abate compared to giving lemongrass powder, KEMAS, 7 (1), 91-96.

6. Santhi, NMM, Darmadi, IGW, \& Aryasih, I. 2014. The Influence of Community Knowledge and Attitudes about DHF on Mosquito Nest Eradication Activities in Dalung Village, North Kuta District, 2012. Journal of Environmental Health, vol.4 No.2, pp. .152-155.

7. Gesriantuti, N., Badrun, Y., \& Fadillah, N. 2017. Composition and Distribution of Aedes Mosquito Larvae in Dengue Hemorrhagic Fever Endemic Areas in Pekanbaru City. Photon: Journal of Science and Health, 8 (01), 105-114.

8. Kinansi, R. R., \& Pujiyanti, A. 2020. The Effect of Characteristics of Water Reservoirs on Density of Larvae Aedes $s p$. and the Risk of Dengue Hemorrhagic Fever Spread in Endemic Areas in Indonesia. Balaba, 16 (1), 1-20.

9. Mading M., Kazwaini M., 2014. Ecology of Anopheles spp. in Central Lombok Regency. Aspirator. 6 (1): 1320. 